\title{
FORMAÇÃO DE PROFESSORES E RELAÇÕES INTERPESSOAIS
}

\author{
Maria Aurora Dias Gaspar
}

Mestre em Educação - PUC-SP; Professora do curso de Pedagogia - Uninove;

Assessora Pedagógica - Instituto Paulo Freire.

auroragaspar@hotmail.com auroragaspar@uninove.br

\section{Resumo}

Este artigo discute aspectos relevantes à formação docente, considerando o âmbito das relações interpessoais entre professor-aluno e seus desdobramentos. As relações interpessoais devem ser entendidas como momento fundamental do processo de formação dos professores, uma vez que colaboram para a construção de sua identidade pessoal e profissional. Dessa forma, as relações interpessoais, tanto quanto a capacidade técnica e teórica, constituem elementos essenciais à formação de professores.

\section{Palavras-chave}

Formação de professores. Relações interpessoais e afetividade. Relação professor-aluno.

\section{TEACHERS' FORMATION AND INTERPERSONAL RELATIONS}

\begin{abstract}
This article discusses the relevant aspects of teachers' formation, considering the scope of interpersonal relations established between teacher-student and the unfoldings emerged from the established relations. The interpersonal relations must be understood as a fundamental moment of the teachers' formation process, as they collaborate for the construction of their personal and professional identity. Thus, the interpersonal relations must be understood as essential elements in the teachers' formation, as well as their technical and theoretical qualification.
\end{abstract}

\section{Key words}

Interpersonal relations and affectivity. Teachers' formation. Teacher-student relation. 
É difícil precisar quando e como o mestre torna-se um mestre... A força do mestre é uma responsabilidade assumida. Primeiramente, responsabilidade para com os outros, pois o mestre descobre que ele tem responsabilidade de alma. Vivia até então confiando nos outros; agora, são os outros que devem confiar nele. (GUSDORF, 1995, p. 85).

\section{Introdução}

O ser humano, ao longo de sua formação, tem recordações privilegiadas que justificam sua existência - recordações da família, dos amigos, das experiências amorosas e do tempo da escola constituem vivências de grande importância, especialmente esta última.

Cada um de nós conserva imagens inesquecíveis dos primeiros dias de aula e de todos os anos escolares que contribuíram para o nosso desenvolvimento como pessoas e como profissionais. Aquilo que nos ensinaram, o conteúdo teórico propriamente dito, muitas vezes é esquecido, mas quando adultos nunca esquecemos o dia-a-dia da escola: os amigos, as aulas, o recreio, as bagunças, as brigas, as broncas, os jogos e os professores. Ficam na lembrança os professores que um dia fizeram a diferença em nossas vidas; na memória, guardamos afirmações importantes e exemplos decisivos desses educadores, expressos em atitudes, sorrisos, palavras de censura ou conselhos que repercutem em nossa vida adulta.

Gusdorf (1995) argumenta que o professor, queira ou não, torna-se um modelo para o aluno, em especial na sociedade contemporânea, na qual os próprios pais delegam a ele muitas responsabilidades, que o fazem ser muito importante na vida de cada um de seus alunos. Por isso, ao longo de toda a vida, o ser humano guardará uma saudade fiel daqueles que para muitos foram os primeiros sustentáculos da verdade, os guardiões da esperança humana. Assim, falar da importância das relações interpessoais na formação de professores, no momento atual, é de extrema relevância, uma vez que o palco das discussões na área educacional desvela a prioridade na modificação desse processo formativo, que tem como tarefa desafiadora formar o professor no e do mundo contemporâneo. 
A formação de professores é influenciada por inúmeros fatores e, dada sua complexidade, muitas variáveis que interagem nesse processo nem sempre são suficientemente compreendidas, e entre elas está a relação professor-aluno.

Quando olhamos as relações na educação, do ensino fundamental ao ensino superior, observamos quão desgastadas estão, baseadas quase que somente no ensino de conteúdos, os quais se encontram, muitas vezes, calcados em conteúdos fatuais, sem nenhum significado ou sentido para alunos e professores. As queixas já comuns de professores do ensino superior sobre as atitudes de seus alunos, que só valorizam notas, parecem advir de tempos longínquos, quando, como alunos da educação básica, não tiveram a oportunidade de discutir os valores que engendram as relações comuns, em espaços de convivência coletiva. (SOUZA, 2002, p. 37).

No Brasil, nos últimos 20 anos, o exercício da docência no ensino superior tem demonstrado a necessidade de considerar os alunos em sua totalidade, ou seja, também no aspecto afetivo, pois dessa forma expressam suas angústias, medos, sonhos, ilusões, projetos de vida; o aspecto cognitivo demonstra suas expectativas profissionais, níveis de conhecimento e aproveitamento do curso e as dificuldades inerentes a esse processo; o aspecto social apresenta a dinâmica das relações sociais e individuais na sociedade capitalista contemporânea, em especial no Brasil. Nos termos de Almeida e Mahoney (2002, p. 86):

Somos pessoas completas: com afeto, cognição e movimento, e nos relacionamos com um aluno também pessoa completa, integral, com afeto, cognição e movimento. Somos componentes privilegiados do meio de nosso aluno. Torná-lo mais propício ao desenvolvimento é nossa responsabilidade. 
O papel das relações interpessoais necessita não apenas ser discutido teoricamente, mas vivenciado diretamente na relação professor-aluno, para que se estabeleça uma relação de confiança e autoridade. Isso pressupõe uma atitude de confiança na capacidade que as pessoas possuem de explorar e compreender a si mesmas e seus problemas, bem como em sua capacidade de solucionar esses problemas em qualquer relação próxima, duradoura em que se possa promover um clima de calor e compreensão autênticos, tal como proposto por Rogers (1974).

É dessa capacidade que as pessoas necessitam para repensar sobre si mesmas, autocompreender-se e promover modificações atitudinais que poderão favorecer ou não o contexto da situação de ensino-aprendizagem. São comuns, na fala de muitos alunos, frases como: "O professor sabe muito, mas não consegue chegar até mim"; "de que adianta tanto conhecimento, se ele não consegue me cativar na sua aula?”. O professor precisa, na relação dialógica com o aluno, ser por inteiro e falar não apenas verbalmente, mas também corporalmente, englobando suas emoções, sentimentos e paixões em sua relação com a cognição.

\section{A importância das relações interpessoais na formação de professores}

O tema relações interpessoais na formação de professores tem sido pesquisado com maior intensidade nos últimos dez anos, e tais estudos indicam a necessidade de entender determinados sentimentos, como amor, ódio, amizade e a importância destes na vida humana. Essas relações correspondem a um conjunto de procedimentos que visa a facilitar a comunicação e a linguagem, estabelecer laços sólidos nas relações humanas e criar uma linha de ação sobre as bases emocionais e psicopedagógicas, garantindo, assim, uma visão sistêmica e integrada do ser humano. No entanto, quando nos referimos às relações interpessoais, entramos numa seara de complexidade, porque o ser humano é uma figura ímpar, ser singular no imenso espaço que emoldura nossa passagem pelo tempo. Essa originalidade de cada um dificulta a comunicação interpessoal e com ela todo esquema de relações humanas que envolvem o segredo do conviver. 
Os laços entre alunos e professores se estreitaram na imensa proximidade desse imprescindível afeto, e tornou-se importante descobrir as ações, estratégias, procedimentos sistêmicos, reflexões integradoras que possibilitassem ir além de um singelo "sou seu professor e gosto muito de você." As relações que envolvem alunos e professores, professores e professores, professores e pais e ainda muitos outros 'atores' do universo escolar são marcadas pelo imprevisível; por isso, nem sempre é possível antecipar o uso de uma ação ou estratégia que atue como sensibilizadora nas relações interpessoais.

Na formação de professores, um requisito fundamental para as transformações que se fazem necessárias na educação é entender o aluno como indivíduo. Além disso, a relevância das relações interpessoais que se estabelecem entre ele e o educador precisa ser conhecida em sua real significação para que o interagir entre ambos ocorra. Essas formas novas de significar o mundo supõem novos modos de ser, sentir, pensar, valorizar e agir que, necessariamente, trazem consigo novos valores, sonhos e comportamentos assumidos por um número cada vez maior de pessoas e comunidades, como assegura Leonardo Boff (1996).

O educador, para poder promover o desenvolvimento global de seu aluno e priorizá-lo no âmbito das relações interpessoais, necessita primeiramente conhecer a si mesmo. Quando repensa suas atitudes, sua prática cotidiana e seu comportamento, sua expressão verbal e não-verbal pode ressignificar internamente os modelos de compreensão acerca das ações de seus alunos. Faz-se necessário refletir sobre as relações interpessoais, sobretudo nos espaços educacionais, pois são inúmeros os conflitos que têm marcado o início do século XXI, indicando a necessidade de repensar a dimensão humana, e não apenas social e econômica, pois

No campo da formação de professores, temos acesso a estudos e pesquisas sobre o mal-estar docente, sobre as síndromes que abatem a categoria, geralmente resultantes de desgastes, sobretudo na relação professor-aluno. (SOUZA, 2002, p. 37).

Almeida (2000) avalia que a formação dos professores deve valorizar o papel das relações interpessoais e a relação formador-formando, possibilitar um espaço para que ambos se posicionem como 
pessoas, uma vez que é na escola que as experiências e os saberes são trocados, validados, apropriados ou rejeitados. Os professores devem partilhar com seus pares as experiências ricas que tiveram no transcorrer de sua vida profissional. Essas situações vivenciadas, quando afloradas, têm uma forte implicação afetiva, o que aumenta as possibilidades de releitura da experiência em confronto com as situações do momento presente. Mahoney (1993, p. 68) salienta que:

O sentimento vai ocupar sempre uma posição central em todos os momentos do desenvolvimento, independentemente de faixa etária. A criança, ao se desenvolver psicologicamente, vai se nutrir principalmente das emoções e dos sentimentos disponíveis nos relacionamentos que vivenciam. São esses relacionamentos que vão definir as possibilidades de a criança buscar, no seu ambiente e nas alternativas que a cultura lhe oferece, a concretização de suas potencialidades, isto é, a possibilidade de estar sempre se projetando na busca daquilo que ela pode vir-a-ser.

Almeida (2001) enfatiza em seus estudos que as conversas de corredor e os intervalos são situações de relações interpessoais intensas para os alunos. O espaço entre a sala dos professores e as portas das salas de aula proporciona conversas informais que intensificam essas relações; as conversas de corredor são apontadas como momentos de interação muito ricos, geralmente mais ricos do que as reuniões maiores como o Horário de Trabalho Pedagógico Coletivo (HTPC). ${ }^{1}$ A autora mencionada cita sua experiência como aluna e como profissional, destacando a necessidade de desenvolver determinadas habilidades, atitudes, sentimentos que são o sustentáculo da atuação relacional: olhar, ouvir, falar e prezar.

Na tarefa de coordenação pedagógica, de for-

1 São reuniões coletivas realizadas na escola pelos professores da rede pública de ensino estadual paulista, nas quais a proposta é avaliar e discutir a dinâmica da prática docente, da aprendizagem dos alunos e da organização da unidade escolar. mação, é muito importante prestar atenção no outro, nos seus saberes, nas suas dificuldades, nas suas angústias, no seu momento, enfim. [...] Há outra questão a considerar: a amplitude do olhar. Ou seja, há um olhar imediato de curto alcance, um olhar que nos faz chegar às pessoas e aos problemas do cotidiano. Mas há outro olhar, 
mais amplo, que nos faz projetar o futuro, o que desejamos construir a médio e longo prazos. (op. cit., p. 71).

Em obra anterior, Almeida (2000, p. 79) já discutia a dimensão positiva do ouvir:

Quando alguém é ouvido (e compreendido), isso traz uma mudança na percepção de si mesmo, por sentir-se valorizado e aceito. E, por sentir-se valorizado e aceito, pode apresentar-se ao outro sem medo, sem constrangimentos.

O olhar atento e o ouvir são pré-requisitos para uma fala significativa do professor:

o quanto as pessoas, em diferentes contextos, principalmente no contexto de formação, querem ser consideradas, vistas, ouvidas, querem receber uma comunicação autêntica; enfim, o quanto elas desejam ser percebidas como pessoas no relacionamento, e quanto esse tipo de relacionamento traz como ganhos. (ALMEIDA, 2001, p. 77).

Rios (2001, p. 59-60) informa que:

a relação pedagógica é, sem dúvida, uma relação privilegiada, uma proximidade específica [...] o aluno se lembra do tom da voz do professor, de seu jeito de escrever na lousa, e não de suas lições de filosofia, de geografia, de história, de didática...? Sem dúvida, são importantes aquelas características que o fazem lembrar do convívio, sim, mas do convívio por inteiro, do conhecimento que ele tem oportunidade de receber e construir com o professor no diálogo dos corpos educativos.

Para a autora, a idéia de conteúdos não se restringe apenas aos conceitos, mas engloba comportamentos e atitudes: 
Ao lado da razão, a imaginação, os sentimentos, os sentidos são instrumentos de atuação na realidade e criação de saberes e valores. O bom ensino será, então, estimulador do desenvolvimento desses instrumentos/capacidades. (op. cit., p. 61).

O professor deve rever suas expectativas em relação ao aluno, pois, na medida em que o trata como pessoa, considerando o ser global, com seus sentimentos particulares, e intensifica suas relações interpessoais de amizade, confiança, respeito, empatia, autenticidade, favorece a aprendizagem e o crescimento pessoal. Essas expectativas do professor em relação ao aluno funcionam como profecias autorealizadoras. Os estudantes, por sua vez, acreditam na possibilidade de aprendizagem e crescimento pessoal e estabelecem, na relação com o professor, atitudes e comportamentos para corresponder a essas expectativas. Os resultados do estudo de Almeida (1990, p. 4) demonstram que:

ao aluno não basta que o professor explique bem sua disciplina; ele quer também, e principalmente, que o professor o respeite, valorize, compreenda, mantenha comunicação com ele. A dimensão atitudinal/afetiva é extremamente valorizada pelos alunos, ainda mais quando eles se lembram daquele que foi o seu pior professor, carregando nas atitudes negativas de relacionamento. As descrições dos alunos do seu melhor e pior professor revelam que os alunos têm necessidades em relação aos seus professores, necessidades que, para serem satisfeitas, exigem uma relação professor-aluno que envolve conteúdo e sentimento.

Mahoney (1993, p. 71) enfatiza que a relação professoraluno precisa ser mediada pelos conteúdos escolares, pois são eles que "marcam os contornos definidores da ação pedagógica na escola." A relação educativa precisa ser solidificada com um determinado conteúdo que evidencie a autoridade do professor, plena de competência. Com essa atitude de compromisso com a escola, o professor assume diante dos alunos uma condição facilitadora no processo ensino-aprendizagem. 
Não se pode deixar de salientar que relações interpessoais não se ensinam, mas são vivenciadas na relação professor-aluno. Nessa direção, o processo educacional deve, portanto, possibilitar o autoconhecimento por parte do professor, a fim de que possa dar sentido àquilo que faz. Para que isso ocorra, o essencial é o professor caminhar com sentido, isto é, é preciso sentir e sentir com nossos sentidos. Nas palavras de Prado (2002, p. 63):

Caminhar com sentido significa, antes de tudo, dar sentido ao que fazemos, compartilhar sentidos, impregnar de sentido as práticas da vida cotidiana e compreender o sem-sentido (nonsense) de muitas outras práticas que aberta ou sorrateiramente tentam se impor.

Almeida e Placco (2002, p. 49) afirmam que os professores necessitam de aprimoramento das relações interpessoais, com melhor integração entre o pensar, o sentir, o agir e o ouvir ativo "que representa a escuta do pensar, do sentir, do ser do aluno", e "um olhar atento, que vai além do visto, do dito, do escrito." No processo educacional, as relações interpessoais fazem cumprir esse papel: através do outro, que é o professor, o aluno passa a saber quem é ele mesmo; os outros são nossos espelhos; no entanto, poucos são os alunos que podem conhecer e ser percebidos por meio do professor, pois muitas vezes este não lhes dá a imagem refletida para que possam saber quem são. Como nos diz João Guimarães Rosa (2001, p. 122):

Sim, são para se ter medo, os espelhos. Temi-os desde menino, por instintiva suspeita [...] o espelho inspirava receio supersticioso aos primitivos, aqueles povos com a idéia de que o reflexo de uma pessoa fosse a alma. Via de regra [...] é a superstição fecundo ponto de partida para a pesquisa. A alma do espelho-anote-a esplêndida metáfora. Outros, aliás, identificavam a alma com a sombra do corpo; e não lhe terá escapado a polarização: luz-treva.

As relações interpessoais devem ser consideradas elementos norteadores na formação de professores, pois são, ao lado da capacitação técnica/teórica, fundamentais para a construção da identidade 
do professor. Ser professor é ser, antes de tudo, aquele que cativa o outro, no caso o aluno, para a experiência do conhecimento, sendo, em contrapartida, cativado pelo aluno para a continuidade desse trabalho. Nessa perspectiva, as relações interpessoais são a maneira pela qual professor e aluno propiciam a oportunidade de tornar a relação ensino-aprendizagem um momento de conquista do conhecimento, mas pautada na satisfação pessoal e profissional.

\section{Considerações finais}

O estudo teórico e a vivência prática das relações interpessoais constituem elemento imprescindível na formação de professores tanto da educação básica quanto do ensino superior, pois, aliados ao conhecimento teórico/técnico da área de conhecimento, são de fundamental importância o entendimento e a vivência dessas relações.

Por se tratar de tema recentemente estudado na literatura sobre formação de professores, as relações interpessoais são imprescindíveis para explicar e entender grande parte dos problemas enfrentados pelos profissionais da educação no exercício das suas funções docentes e administrativas. Acrescentar essa temática à agenda de formulação, avaliação e implantação das políticas educacionais de formação de professores pode representar significativo avanço no entendimento do processo educacional, em especial da relação ensino-aprendizagem, numa perspectiva que privilegia o ser humano como possuidor de sentimentos, sonhos, desejos, necessidades, sem contudo desconsiderar os aspectos legais, administrativos e políticos, isto é, a questão institucional das políticas educacionais. Isso porque é nas ações, intenções, tensões e comportamentos cotidianos dos seres humanos que se constrói a rede de relações interpessoais que materializam, na maioria das vezes, as macro e micropolíticas educacionais, suas repercussões nas salas de aula e nas escolas e, principalmente, na relação professor-aluno.

Essas relações interpessoais devem pautar as políticas educacionais de formação de professores como elemento integrador, ou seja, que acrescenta conhecimentos determinantes, pois são dimensões formativas tão importantes quanto os aspectos institucionais. 


\section{Referências}

ALMEIDA, L. R. A dimensão relacional no processo de formação docente. In: ALMEIDA, L. R.; BRUNO, E; CHRISTOV, L. (Org.). O coordenador pedagógico e a formação docente. São Paulo: Loyola, 2000.

. R. A problemática da afetividade na prática pedagógica: o noturno em escolas de $1^{\circ}$ e $2^{\circ}$ graus. Participação em mesa redonda, Encontro anual de psicologia de Ribeirão Preto, $20^{\circ}$. Universidade de São Paulo (USP). São Paulo: out. 1990.

R. O relacionamento interpessoal na coordenação pedagógica. In: ALMEIDA, L. R.; PLACCO, V. M. S. (Org.). O coordenador pedagógico e o espaço da mudança. São Paulo: Loyola, 2001.

ALMEIDA, L. R.; MAHONEY, A. A. (Org.). Henri Wallon: psicologia e educação. São Paulo: Loyola, 2002.

ALMEIDA, L. R.; PLACCO, V. M. S. As relações interpessoais na formação de professores. São Paulo: Edições Loyola, 2002.

BOFF, Leonardo. Ecologia: grito da Terra, grito dos pobres. São Paulo: Ática, 1996.

GUSDORF, G. Professores para quê? Para uma pedagogia da pedagogia. São Paulo: Martins Fontes, 1995.

MAHONEY, A. A. Emoção e ação pedagógica na infância: contribuições da psicologia humanista. Temas em psicologia. v. 3, p. 67-72, 1993.

PRADO, F. G. C. Ecopedagogia e cidade planetária. São Paulo: Cortez, 2002.

RIOS, T. A. Compreender e ensinar - por uma docência da melhor qualidade. São Paulo: Cortez, 2001.

ROGERS, C. Remarks on the future of client-centered therapy. In: WEXLER, D; RICE, I. Inovations in client-centered therapy. New York: John Willey and sons, 1974.

ROSA, João Guimarães. Primeiras estórias. Rio de Janeiro: Nova Fronteira, 2001.

SOUZA, V. L T. Relações interpessoais e universidade: desafios e perspectivas. In: ALMEIDA, L. R.; PLACCO, V. M. S. As relações interpessoais na formação de professores. São Paulo: Edições Loyola, 2002. 